\title{
Like, comment and share: Understanding language learning experience of gifted students through massive open online course (MOOC) platform
}

\section{APA Citation:}

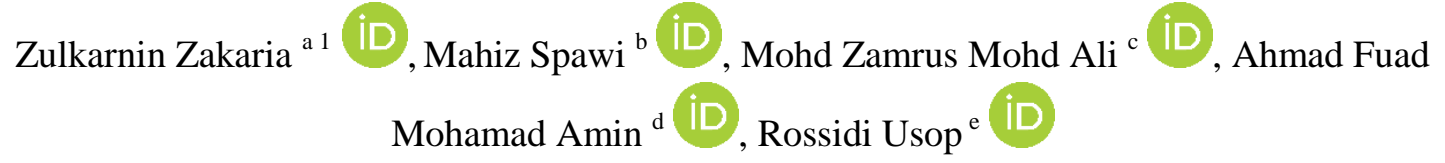

${ }_{a, b, c, d, e}$ Kolej GENIUS Insan, Universiti Sains Islam Malaysia, Malaysia

\author{
Zakaria, Z., Spawi, M., Ali, M.Z.M., Amin, A.F.M., Usop, R. (2021). Like, comment and share: Understanding language learning experience \\ of gifted students through massive open online course (MOOC) platform. Journal of Language and Linguistic Studies, 17(3), 1440-1456. \\ Doi: $10.52462 / j 11 s .104$ \\ Submission Date: $18 / 05 / 2021$ \\ Acceptance Date:28/08/2021
}

\begin{abstract}
Massive Open Online Course (MOOC) gained prominence as an alternative teaching and learning platform for many educators embarking on developing university courses online. In Malaysia, the initiative at lower secondary school was quite recent and not many teachers were willing to invest the time and effort to develop the MOOC courses. This study examined the secondary school gifted students' experience in learning a language subject using a new online course in a MOOC platform. All students from the lower secondary levels of a gifted education institution enrolled in the English subject MOOC and their engagements and experiences were recorded in their journal and classroom discussions. Their text and verbal responses were analysed and reported to better understand the various issues and challenges that they had encountered. Students accredited certain positive aspects of MOOC and they found it to be useful, flexible and engaging. More than 80 per cent relished the social meeting elements such as like, comment and share. The contents and activities helped them learn and practise the English language. The study outcomes disclosed the use of MOOC as a social learning platform that offers engaging learning. The online teaching and learning process could benefit from the social media features found in MOOC which are motivating to the gifted students. For educators, this platform offers useful alternatives and strategies to develop their teaching contents online and utilise it as an enrichment programme in the gifted and talented education institution.
\end{abstract}

Keywords: media and education; online learning; gifted students; qualitative analysis

\section{Introduction}

Massive open online courses (MOOC) is a concept that relates to the electronic learning or elearning that has become popular in the field of educational technology. Education and technology are not really meant to be together because the technology inventors did not design their hardware and software with teachers, students and their classroom in mind. The struggle for educators has always been with the challenge of finding compatibility with what have been designed and produced for the mass market. While educators have been busy with the effort to integrate technology into the

\footnotetext{
${ }^{1}$ Corresponding author.

E-mail address: zulkarnin@usim.edu.my
} 
classroom with various form of hardware and software, the internet presents a platform to bring the classroom to the world wide web, a playground for variety of contents, ideas and creations. It is a world that moves away from the reliance of traditional form of media consumption like radio and television. Still, websites were once too technical for the layman and teachers included. The framework and platform are there yet too complicated for many to get their hands dirty with the settings and programming. Today, the transformation of the internet and its platform have made many technical adventures simpler and possible even for the not-so-tech-savvy educators to use the available online channels and platforms.

In today's educational environment, educators have the luxury of choosing from abundance of available hardware and applications which are streamlined towards teaching and learning. The concept of ubiquitous learning is common and there are platforms like the massive open online courses (MOOCs) that enable educators to plan and implement their classes online. Educators have also implemented MOOC to produce meaningful experience in blended learning. Earlier studies reported elearning as an impactful way to enrich learning (Garrison \& Kanuka, 2004; Gilbert \& Flores-Zambada, 2011; Morris, 2014; Sharpe et al., 2006). Zawacki-Richter and Naidu (2016) listed MOOCs as a major emerging platform from 2010 to 2014, as discovered in publications for the last 35 years. The growing development now is exploring MOOCs implementation possibilities to enrich traditional classrooms. It could be used as additional resources for both teachers and students.

\subsection{Gifted Education}

Gifted education presents a carefully developed curriculum to cater to the needs and requirements of the individuals in the programme. The accelerated, compacted and enriched curriculum are meant to assist the students to the gifted students in developing their high intelligence level and potentials. The syllabus and contents are usually prepared for advanced level and carried out using various teaching strategies and activities such as differentiated learning and assessments (Van-Tassel Baska and Brown, 2009; Beecher and Sweeney, 2008; Worrell et al., 2019). STEM subjects have been the focus in early gifted programmes. To ensure the success of services offered to gifted students, educators plan and design various accelerated and enriched programme inside and outside the classroom. The syllabus, tasks and assignments are crucial to help gifted students fulfil their expected potential.

Studies in gifted education indicated that they would likely perform well in STEM, leadership, arts or language (Renzulli, 1997; Van-Tassel Baska, 1992; Worrel et al., 2019). The tend to venture into higher level of content learning and prefer challenging and difficult tasks normally prepared in typical lessons. With the right materials and activities, they could show skills and abilities beyond their age group and level (Renzulli, 1997; VanTassel-Baska, 1992; Gagne, 2005). Educators are trained to work on various projects and activities aim to supply gifted students the advanced level tasks that would match the actual potential and ability. Having gifted programme services that constantly challenge them are the keys to continuously enhance their learning experience because they learn and think faster, with high sensitivities (Renzulli, 1997; VanTassel-Baska, 1992; Gagne, 2005; Yazid, 2017, Noriah et al., 2009). Every gifted programme is accounted to provide all the required services that cover their physical, emotional, spiritual and intellectual needs of the gifted individuals.

STEM subjects have been the main focus in various gifted programmes all over the world (Yu \& Jen, 2020; Tan et al., 2020; Rambo, 2019; Taber, 2020). This is common since the programme stakeholders believe that the best way to develop the 'smartest' individuals in the country with the advancement and science and technology. Mastering these areas would also mean being in the frontier of knowledge and being the lead in human race. To achieve this noble goal, the gifted students would require the language and communication skills that enable them to learn and acquire knowledge from 
various form of resources available. The self-regulated learning skills are high among the gifted due to their preference in understanding a certain topic at deeper level and form their understanding on their own. The language skills would allow them to read and synthesise the materials and later discuss it with their peers and teachers. The support from language learning aspect should also be taken into consideration as the tasks and assignments they work with would require higher language skills and abilities. The language skills should prepare them for their advanced learning, and it should also be synchronously developed with the level of contents they acquire. Thus, the gifted students must be exposed to language learning skills and activities which are available in many forms and platforms in the world of academic. The reliance on old textbooks and references should be supplemented with the digital form of learning materials in the various forms of learning systems and applications.

\subsection{Problem statement}

Gifted programme is designed to assist gifted students with various services that could help them to develop their skills and potentials to its highest level possible. While the community of gifted students would be placed and grouped under the same roof, each individual still requires different level of attention and learning needs. Just like other normal students, educators and course designers still have to consider the physical, emotional, spiritual and intellectual aspects of gifted students. Bear in mind, there are many strategies to achieve this holistic goal in the education programme. There are accelerated and compacted syllabus designs to match their cognitive level and enriched activities and assignments to complement it (Olenchak \& Renzulli, 1989; VanTassel-Baska, 2003; VanTassel-Baska \& Brown, 2009). Still, there are individualistic consideration to make, and the educators must prepare flexible activities and assignments to accommodate diverse needs of each individual. Some independent learners would prefer activities that they could explore deeply and independently. This study surveys the use of a popular social learning platform of MOOC among the lower secondary gifted students. The online English course was available on a platform called SK OpenLearning (www.skopenlearning.com). Their learning experience on the online platform was used to understand how they could personally utilise the available features on the course and how it would affect their overall English learning practice.

Choosing and developing the right tasks for gifted students would determine the success of the enrichment programme (Tan et al., 2020). Online social platform offers a new dimension in language learning activities because it has many useful communication elements that cover the main language skills of reading, writing, listening and speaking (Periathiruvadi \& Rinn, 2012). Learning independently and reading to discover more information through printed and online materials suit the gifted students' learning style. With a social learning platform, gifted students would be allowed to challenge themselves to discover various activities integrated in the online course. At the same time, they would also get to practice their social skills using the available services equipped in various forms in the platform. Thus, this study assesses the effectiveness of multiple features of MOOC for language learning tasks and online communication. The research objectives for this study were as follows:

i. What are the important elements of online language learning platform for gifted students?

ii. How does social language learning platform assist gifted students in their learning experience?

\section{Relevant Literature}

The definition and conceptualisation of giftedness are still debated by scholars and academics in this education paradigm. Most gifted programme would use their cultural context and values to define the objectives and purpose of such programme in the country. Government-backed gifted programmes are subject to the educational policy existed in the mainstream education programme in the country. 
The GENIUS Insan gifted programme has to deal with the same situation with its programme implementation. The students' intake policy for Muslim students with the intelligence test score of 130 and above should take into consideration their Quran recitation and memorisation skills and ability. The academic performance in this college would mean that the students are expected to perform as well in their Quran education programme. The college employs the same grouping strategy for those who have been accepted into the programme. For academic and Quran education, the college adopts Kulik and Kulik (1992) grouping strategy and they are assigned by their own age levels and Quran memorisation ability. The grouping strategy is meant to help them to assimilate into the system of academic and Quran education grouping. The Quran classes carry out different goals and assessments for their syllabus and the components would relate closely to the memorisation and recitation quality of the students. In another word, the class grouping will be different in academic and Quran classes. The intelligence score matters for the academic grouping while the memorisation pace and recitation quality would determine the grouping for their Quran classes.

The grouping strategies are important in a gifted and talented education programme since it would determine the performance of individual students in the classroom setting in their classroom environment. The general grouping methods would be effective to some students and might not work with some small group of students or individuals. Thus, it is very important for administrators to monitor students' performance in the grouping settings as discussed here:

1. Multilevel classes. Students are divided into similar grade groups based on their ability - high, middle, and low. They will learn in separate classes with a standard timetable.

2. Cross-grade grouping. Students are grouped using their achievement level, based on subjects and the classes would consist of mixed-level students.

3. Within-class grouping. Small groups in a classroom and teacher would manage them using their aptitude level.

4. Enriched classes. Learning experiences would be planned and implemented based on students' aptitude level and performance. Learning contents are flexible and more personalised.

5. Accelerated classes. Students will go through content acceleration based on their cognitive ability. The educators will assist students to cover higher level contents in this classes regardless of students' age level.

(Kulik and Kulik, 1992)

Once identification process has been done in a gifted programme, students grouping would be further mould them into the system of gifted curriculum. All aspects of the gifted programme are designed to help gifted students fulfil their true potential. Educators understand that the key to the implementation success could rely on the materials, activities and assessments prepared. The strategies in teaching and learning of gifted students include accelerated programme. This is typical practice in other gifted education programme as well because experts believe that these individuals are always capable to understand their contents at higher pace and advanced level. Their ability is well-suited to assist them in achieving the learning goals at accelerated level compared to their peers of similar age group. Another approach in gifted education programme is the differentiation in class instructions. The educator has the ability to identify the individual strength and inclination of each student and prepare suitable materials and instructions that match the cognitive level and learning style. This is where the enrichment programme helps in presenting the learning experience that allow the advanced students to discover their learning contents in detail and much deeper compared to the prepared syllabus.

\subsection{Gifted students learning needs}


Needs and requirement of each gifted student vary from one person to another and the gifted education programme is developed to meet them so that they will perform in their academic endeavour (Reis, 2007; Yoon, Kim \& Koo, 2020). From past research, majority of teachers claimed that their highly gifted were not given classroom materials and instructions that challenged their cognitive ability and therefore stunted the progress in their study (Loveless, Farkas, \& Duffett, 2008). Only educators will understand the need of the cognitively advanced students in their classroom and they should work on preparing suitable activities and instruction that would give the students their expected learning experience (Hertberg-Davis \& Callahan, 2013). Many gifted programmes and educators were not so effective in their preparation of the right enhanced learning resources and assignments for the gifted students with higher ability and expectation (Rotigel \& Fello, 2004).

\subsection{Enrichment Programme}

Jelinek (2013) stressed on the importance of enrichment programme and recommended them in the form of advanced activities and organized pedagogical resources-institutionally and continuously-to be implemented across the standard curriculum. Guenther's elaborated the definition further:

[...] is an intentional and planned stimulation effort that seeks the growth of the child, broadening, deepening and complementing the basic school curriculum with knowledge, information and ideas that make it capable of greater awareness of the comprehensive context of each subject, discipline, or area of knowledge. (Guenther, 2006, p.67).

Renzulli's Enrichment Triad Model is among the earliest enrichment model set to prepare the activities and materials set for the gifted students. He used a concept called the Revolving Doors model as described in the Three Ring Theory of giftedness. This model suggested that differentiation in themes, interest and study would get students to engage in higher level thinking skills (Renzulli \& Reis, 1997). The three types of enrichment activities proposed in this model covered the following type of skills:

- Type I - the basic activities and experiences that allow students to discover different areas of the subject areas they learn.

- Type II - development of new interests and experiences grew from Type I activities.

- Type III - accumulative Type I and II activities create the expanded level of experience producing heightened interest among gifted students who would invest time and effort to research further on the advanced content in their learning process.

Tan et al. (2020) described enrichment programme for gifted students as an effort to cater to their learning needs and requirements. Meeting their needs would nurture the creative thinking ability, promote talents, and boost learning experiences. The proper planning in the preparation of the learning materials and activities would be the key decisions to ensure a gifted education programme would help the participants in getting the most out of the prepared teaching and learning initiative.

\subsection{Technology and Gifted}

The use of technology had always been a prominent aspect in the gifted education programme. As discovered by Periathiruvadi \& Rinn (2012), earlier research indicated the use of technology in gifted programme implementation. In their survey, 24 studies had centred on technology and giftedness. Researchers discovered the vibrant quality of technology in assisting gifted students perform various learning activities, even though the effects were not so clear. However, studies on twice exceptional (cognitive or physical disabilities and gifted) gifted students and their use of assistive technologies were hard to find. 


\subsection{Assistive Technology}

Assistive technology helps individuals in developing their potential and the technology is usually meant to assist those with disabilities (Ellsworth, 2018). Gifted and talented students could also take advantage of assistive technology in their learning environment. Enrichment activities could be planned and developed with the help of assistive technology in the classroom. The assistive technology could be designed as advanced activities and instruction for accelerated learning. It could also provide problem solving and collaboration opportunities for students. For distance and selfregulated learning, the use of assistive technology would be a great option for both teachers and learners.

Online coursework is a form of assistive technology for classroom instruction and enrichment activity for students (Stambaugh and Pierce, 2019). The availability of online resources for students would give them the chance to continue their study independently and carve their strong understanding in the topics of their interest. Content designers and experts could work with programme educators to plan various for enriched and accelerated contents for gifted students.

In addition, specially designed online courses for gifted students would create strong learning interest (Wallace, 2009), develop advanced problem-solving skills, help attain in-depth content, and perform better on Advanced Placement exams (Olszewski-Kubilius and Lee, 2004). The online courses could encourage students to research further on topics of their interest, enrol in courses outside the syllabus, learn based on their cognitive ability (Olszewski-Kubilius and Lee, 2004), and enjoy individualised content (Thomson, 2010; Wallace, 2009).

\subsection{Why MOOC?}

In this research, massive online open course (MOOC) was chosen as the assistive technology for the enrichment activity for students in the college. The online course was developed using the latest Ministry of Education's KSSM curriculum. CEFR framework has been adopted for the guide in all the language skills covered in the syllabus. The online course prepared their contents, activities and features in all the four language skills of reading, writing, listening and speaking throughout the courses. There were elements on grammar and literature as prescribed in the main syllabus in KSSM. All the lower secondary school students of the college were enrolled in the courses developed based on their respective form or level. Students in form 1 and 2 were grouped within their own college classmates and only the form 3 students were put into open group with participation from schools outside the college. This was their first experience in using this platform and any online learning platform.

While MOOC has been featured as online learning platform in higher learning institutions especially in public universities, it is never used in secondary level education in this country. Malaysian public universities had been working on the initiative to encourage online content of each university course to be available online since 2015. Each course was expected to reach the target of $30 \%$ online content to be eligible as blended learning courses aspired by the policy underlined by the Ministry of Higher Education. During this initiative, training and workshops were conducted for the university lecturers to equip them with the knowledge and skills to migrate their course content to the online platform. Some of the courses at the public universities even offered microcredential certification for their academic programmes. MOOC platform has been adopted all over the world and with established universities offering microcredential programmes, it has emerged as a trusted online learning platform for many. This development in blended learning initiative at university level presented a flexible and stable platform for secondary schools teaching and learning resource centre. 


\subsection{MOOC and Social Media Learning}

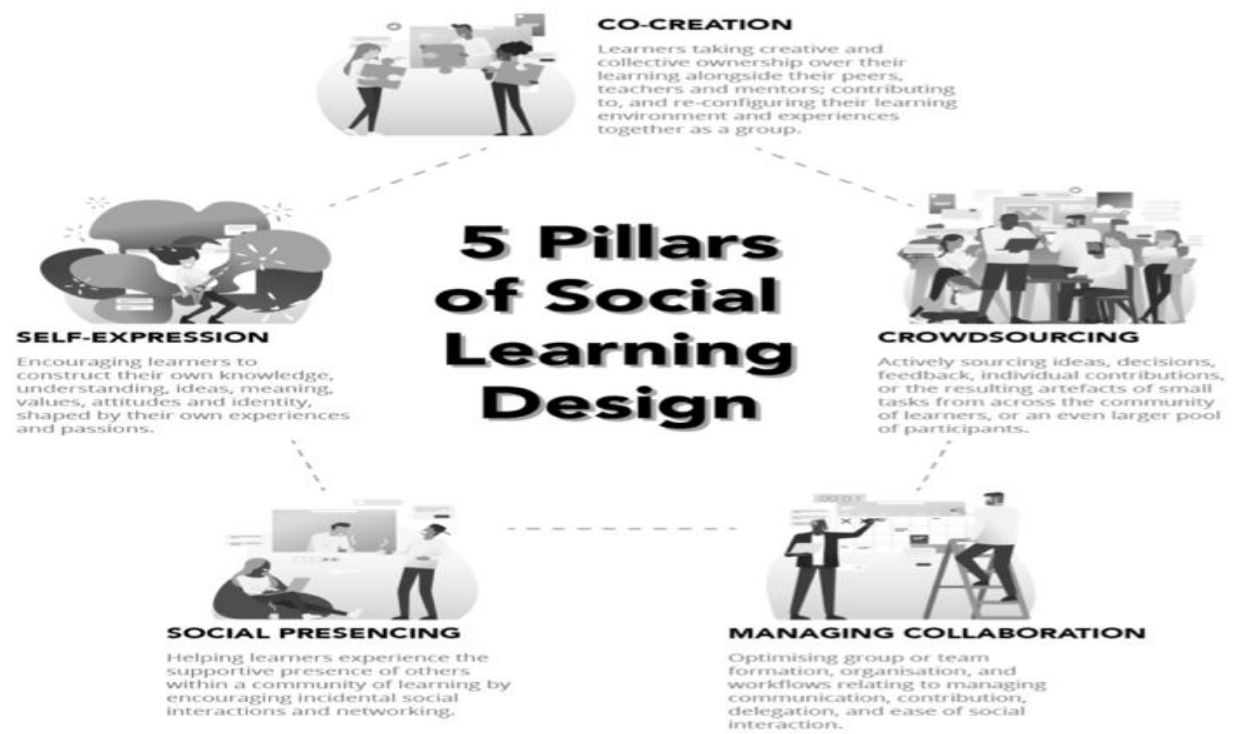

Social media has emerged as a huge influencer in every aspect of human life including education (Mady and Baadel, 2020; Yaacob and Saad, 2020; Zhou et al., 2020).

The young generations have embraced and accepted social media as their way of life. They consume contents from the social media and even adopt values and beliefs from the applications and platforms they use on their devices. Viral videos, postings or pictures had become the main news or reference of the time, hour and day, as social media update took over the 'breaking news' phenomenon because they virtually live their life online 24/7. While most applications and platforms are designed for entertainment, business and marketing, OpenLearning created a learning platform using many of the elements found on popular social media apps and platforms. The guideline prepared for social learning could be adopted in using social learning platform for classroom activities and learning. In 5 Pillars of Social Learning, the elements that should be considered are Co-creation, Crowdsourcing, Managing Collaboration, Social Presencing, Self-Expression. The above diagram explains the basic concept for each element, and they are useful guides for all educators who would like to embark on adopting social learning platform for their teaching and learning activity.

\section{Research Model}

The study employed a mixed method approach to obtain the relevant data through the research instruments. For the general feedback on the use of MOOC, questionnaire was distributed to all participants. To better understand the language learning experience using the online course, the students were asked to record it in their weekly journal entries. This was the qualitative data collection from all students during the research duration (Merriam and Tisdell, 2015; Cresswell and Poth, 2018). The questionnaire developed was asking for students' personal interaction with the various aspects of the online course in their language learning experience. The key features found in the MOOC platform were scrutinised to find out students' general belief of its function and usefulness in their learning progress. There were parts in the questionnaire that requested students' feedback on the availability and usefulness of the platform features such as multimedia and audio components prepared in the content and activity in the course. The other sections in the questionnaire included the communicative aspect of the online learning platform and how peer interaction occurred during their language learning process. 


\subsection{Participants}

All lower secondary students from the college participated in the online language course. They were 56 Form 1 students, 50 Form 2 students and 48 Form 3 who enrolled in the course provided. They were chosen to take part in the online language course to get them to experience MOOC platform as their enrichment activity. The typical language enrichment tasks would include library research and extended writing projects. There were extracurricular activities for communication such as public speaking and debate but the participation from students were not so encouraging and the kind of activities were quite limited and often done offline rather than online. The students were generally quite competent in using either their laptops or tablets to access the specific MOOC. There was a briefing for all students on the common features and samples of activities that they could do, join or participate. They were encouraged to communicate with everyone in the same course. The Form 1 and Form 2 students did not really interact with their friends from other classes and this platform offered them the opportunity to get to know their friends and interact with those they were not familiar with because of the limited chance to communicate in physical classes. Only the Form 3 students had the chance to know more about their batch since their grouping were reshuffled every academic year and they would have known their batch mates from the previous grouping.

\subsection{Data Collection Tools}

The two main instruments used in this study were the questionnaire and reflections written by the students in their learning journal. The questionnaire sections covered the language course contents, social elements, ease of use, and language learning experience. The questionnaire also covered the features and social learning elements found on the platform. There were also asked on the five pillars of social learning experience recommended by Open Learning.

\subsection{Qualitative Data}

Reflections on the gifted students' language learning encounter on the MOOC platform were written in their journal. The weekly entries would revolve around the similar questions listed in the questionnaire. The teacher involved would help students to focus on the topics that students would reflect in their entries. The journal writing activity continued during the duration of their engagement with the language MOOC and it was the routine that the students had been practising as part of language learning activity in the college. Generally, students would record their thoughts and feelings on various aspects of their language learning activities in the online course and compare them to the language learning experience in their typical classroom. They were encouraged to write topics on their difficulties, challenges and confusions when they first started using the platform at the beginning of the research. Once they were familiar with the user interface and the organisation of the MOOC platform, they would write on the contents, activities and tasks that they had to perform. Since the platform utilised features such as rewards and progress, they would also write about the motivational aspect on the learning design on the platform. They were asked to give their comments and opinions on the types of activities and tasks that they would need to accomplish in the units developed in the online course. The students were allowed to criticise and reflect on the communication and collaboration effort with fellow online participants. Since online learning activities and tasks allowed them to hide and not facing their friends face-to-face, they tend to take part in more activities compared to the usual physical class activities. More students enjoyed their non-physical appearance in the online class rather than facing their friends in the physical class. They mainly discussed all these important points in class, and later they were asked to describe them further in their journal writing. 


\subsection{Procedure}

The questionnaire was distributed to the students at the end of the semester when the research period was over. They had been using the online MOOC for about two months as a form of language enrichment activity. The course was mainly accessed during the English language classes for two hours weekly. Some students had also used the course when they were at home during the school semester break. The online questionnaire was answered in class towards the end of the semester and while they had covered more than three learning units prepared in the online course. All students from Form 1, 2 and 3 answered the questionnaire and their feedbacks were recorded and analysed quantitatively using descriptive statistical method. The analysis were reported in the findings section in this paper. For the journal reflections by the students, they were coded manually, analysed into themes for discussion in the following section.

\section{Findings}

For the quantitative analysis, students were asked to relate they experiences with the overall features of the online MOOC. Generally, they responded positively in the questionnaire when they were asked about the four main elements from the course. For their feedback on the course contents, almost all students found the lessons and examples used in the prepared lessons to be interesting and they were engaging for them since this was their first experience using the online platform. Students did not have many problems with the instructions found in the online courses as they managed to follow the tasks and activities without much hurdle. The user interface and placement of menu and other interactive features were among the elements that the students were asked to evaluate in the questionnaire. Basically, they could follow the step-by-step instructions because it was clear and easy to understand. These features were also considered helpful in guiding them from one section to another throughout the online course.

Another important aspect in the online course was the social elements they enjoyed. There were a few prominent features of social elements implemented in MOOC. There were peer engagement, postings, feedback features such as comments and likes and visibility of posts by the user. Among the common traits found in popular social media apps and platforms were similar to the features found in the online learning platform of MOOC. The association made between other social media apps and features available in MOOC actually helped students familiarise themselves with MOOC and therefore get them to be more motivated to explore and perform the language tasks and activities. The common behaviour among young students would be to have the chance to peer onto their friends' shared space. The ability to know and observe others' activities and performance was an important element in their shared learning platform. They tend to discover what their friends had managed to accomplish in their learning journey and discuss it among their friends. They also liked to view the posts made their friends and responded to those posts. To them, this was an act to support each other in the language learning experience. This feature would also give them the chance to comment and like the posts made by others and it was a very important feature they enjoyed as it brought more meaning to what they experience and feel.

In addition to the earlier features, the students felt that they were at home when it comes to userfriendliness of the platform. The user interface looked and felt familiar, and they could straightaway go through the contents and the tasks prepared in the units of lesson. Some students however reported the challenge to go through the organised contents because of the multi-sections and parts in the units. It could be due to the separate lesson sections arrangement for first-time users and it took them some time to get themselves comfortable with the overall course features. 
In the final section of the questionnaire, students responded to the language learning contents and activities available on the learning platform. The questions set for this section focus on various aspects of the language learning contents, activities and assignments. Since the online language course was a self-paced learning course, many students enjoyed the experience because they were not pressured to complete the activities and tasks within a specific amount of time. They did like the varieties in the activities of the language lessons. Even the presentation of language learning contents felt different because of the multimedia elements used. For students with diverse learning styles, this was a warm welcome for them compared to the usual learning experience using standard reference and language activities workbook. The platform offered a richer experience gained by the gifted students due to the multiple approaches in contents presentation and instructional design.

Table 1. Summary of Questionnaire findings

\begin{tabular}{|l|l|}
\hline MOOC Feature & General views and responses in questionnaire \\
\hline Contents & Engaging lessons \\
& Easy to follow instructions \\
\hline Social elements & Peer engagement features \\
& Preview others' work \\
& View posts and responses \\
& Receive and give comments and likes \\
\hline Ease of use & Easy platform navigation \\
& Easy to find lesson \\
& Easy to locate activities and tasks \\
& Easy to post comments and responses \\
\hline Language learning & Effective lessons and activities to learn English \\
\hline
\end{tabular}

\subsection{Findings from the journal reflection}

Students reflection was conducted simultaneously with their MOOC learning session to ensure they record their immediate feelings and thoughts (Tracy, 2020; Merriam and Tisdell, 2015; Creswell and Poth, 2018). The different forms involved dealt with different difficulties and challenges when they started using the platform. The Form 1 students generally were confused with the features and organisation of the online courses because of a few reasons. Most of them were using their computers for the first time and they had yet to understand their own computer. They were also not familiar with the online platform because definitely they were not active users of the internet and social media apps and platforms. The whole process of registering, logging in and understanding the instructions were too much to handle at the beginning and they had to go some familiarisation phase before they could actually go through the lessons on their own. The Form 2 and Form 3 students just needed a few attempts and some discussion with their peers initially, to embark on their journey of language learning discovery. In short, they were more determined to succeed in the online language learning platform from the word go. They relied on their peers to solve their own confusions and were more independent in their learning. The young students wrote about their frustrations and stress in understanding their own device and the new online learning platform. Their progress was a bit slow at the beginning and slowly picking up after a few sessions.

The second main theme discussed in many of the students' entries were on the language learning features, contents, activities, and tasks. The students tend to make comparison with their usual language workbook or activity book with the ones they discovered in the online course. The interactive features and the flexible arrangement of the platform sections and organisations were among their favourites when they go through the learning units. The contents' presentation that appeared in multimedia forms and creative touches were a breath of fresh air to the students. There were varieties in the forms of activities provided in the course. The activities such as games, puzzles, video contents 
and audio visual were so engaging as they ploughed through them at their own time and pace. Students wrote about their excitement in completing the activities and contents.

Another important theme they noted in their journal was the communication and interaction experience that they had with their friends. The online communication was more preferred to the faceto-communication because they felt less intimidated and more relaxed when they chatted and discussed using the online form. They also got the chance to support their friends in the form of likes and comments that they could post on their friends' work and effort. For the new Form 1 students, these interactive elements were quite refreshing because they would feel less stressful trying to connect with their classmates and friends of the same grade. They could also collaborate with their friends online doing activities such as group work and assignments. The positive encouragement from their friends and teacher was more rewarding in the online course platform. Expressions in the forms of emoticons, gestures and communication symbols were meaningful for almost all students. The new refreshing language learning adventure on the MOOC was generally satisfying and significant for all students.

\section{Discussion}

Sosas (2021) conducted a study on the use of activities based on current social media platform in teaching speaking skills in language classroom. The influence of available technologies and applications such as podcasts, video conferencing, videos and speech recognition were very prominent in students' language learning adventure today. The available videos on platform such as YouTube and Facebook were a huge teaching and learning resources that could be carefully adopted for developing language skills such as listening and speaking. The same environment using the MOOC platform could generate similar outcome because the learning activities and assignments in the online course also made use of the available resources from the internet. Authentic educational videos are available online and they have been produced by many reliable educational institutions and organisations from all over the world (Yaacob and Saad, 2020). The concept of a huge online library is made possible with the various websites, platforms and applications created on the internet and they offer immense potential as existing resources available for educators and students to expend.

Another important aspect of online learning platform would be the motivational effect on students. Similar to the previous research by Housand and Housand (2012) on gifted students, this study reported the same pattern of motivational elements produced by various factors in the use of the online language platform. Gifted students tend to show independence and perseverance in following through a project or topic of their interest. There was a big percentage of gifted students who enjoyed the collaboration and cooperation among their peers in the online learning environment. The peer communication and interaction became the encouragement for them to use the online course and go through the activities in the platform. Their motivation in learning helped them build the confidence in the online learning environment even though it was a new experience for them.

Other than that, another important pattern of behaviour found among the gifted students was their learning style dealing with the online materials on the online course (Kamis et al., 2021). Gifted students displayed strong interest in multimedia and audio-video presentation of learning contents. Listening through recorded audio, elements of background music and effects, watching the content videos were more engaging and satisfying for majority of them. This helped create strong interest in the topic they dealt with and sustain their focus on the tasks and activities they had online. The young generation of students are easily attracted to the online materials which are highly interactive because they preferred the multimedia forms of learning contents. To them, technology elements have become 
the fundamental tool in their daily tasks and having it in their learning environment would be a welcome change to the overall learning experience (Housand and Housand, 2012).

\subsection{Reflections on online learning experiences}

Online language learning was a new experience to many gifted students in KGI. Coming from the primary level, the Form 1 students were 'novice' users in the application of online platform for the language learning lessons and activities. Common themes found in the journal were 'technical issues' such as registration and administration of the platform account. They pointed out the access problems when trying to login for the early phase of using the online course. Not being used to remembering passwords and getting around the system were common problems they met and reported in their weekly reflections. Their consequent effort and strategies were also discussed as they worked on solving all the problems they encountered earlier. By the end of the semester, they were more confident and motivated to access the course and work their way to complete the units of lessons and activities prepared in the online course.

For the young gifted students, especially the juniors in Form 1, the concept of self-regulated learning was a foreign one and they preferred to have guided assistance in getting around the system, understanding the features and going through the activities and tasks together with the teacher. While they were given minimum guidance earlier in the semester, they slowly helped themselves to work individually on understanding the lessons and later deal with the activities they encountered in the units. The communication and collaboration among themselves also got them to be more confident and motivated to use the online platform. Discussion on the best way to accomplish a task would be done online and this was the time when they would use the social interaction elements such as 'like', comment and share with their classmates and students from the same grade. Communication and sharing of ideas and opinions were becoming regular in their online interaction and it also helped them to get to know their friends better. In short, they could improve their language skills with the activities they did in the course and improve their social interaction and communication while performing those tasks together online.

\subsection{Significance of the study}

Language learning experience is supposed to be communicative and interactive. Classroom activities usually require proper planning and it is time-consuming on the teacher's part. With limited time allocation in normal classroom, many students were left with nothing to do when only selected students are called up to join the activities. It would be frustrating for many students because they could not participate in the chosen activities, and they would miss to perform those activities in front of the class. These limitations were addressed effectively using the online language learning platform such as MOOC. The rich features and flexible content development, update and review are giving the opportunities for educators to focus on the development of the lessons, activities and assessment aspects of the subject rather than dealing with the technical aspects on maintaining the system.

Producing the right and suitable materials for the enrichment programme would be crucial in a gifted education initiative and language learning should be designed to be fun and creative. With the correct tool such as a social media learning outlet, educators could also collaborate with educators from other subjects to produce more robust contents and activities across the curriculum. The language learning experience would be made more meaningful when they exist in different context and subjects since the gifted students could choose areas of their interest and work on the topic which get them to invest time and energy to excel in it. The enrichment programme objective will be met once the 
students felt challenged and they grow their knowledge to a greater height with the trigger from the activities and instructions prepared for them.

\section{Conclusion}

Based on the findings and students' views and reflections, it was important to note that MOOC or similar online platform offers a great flexible way of developing courses and could be used as a form of enrichment platform. The materials that could come in various forms encouraged the gifted students to access the online course at regular interval. The activities and other features of the platform were interesting for them and it could generate strong interest for them to complete the prepared activities and encourage them to develop deeper and stronger understanding on the topics of their interest based on the lessons and topics available.

Online language learning could make use of existing social media platforms and apps whether on the internet or mobile devices. The language learning contents could adopt various resources available online and the educator could integrate popular media contents such as YouTube, Instagram or even TikTok to encourage and motivate learners especially gifted students. The young generations' connection with all these media would make them familiar with the platform and the contents, ideas and references that they could tap into and develop their own circle of knowledge. With the guidance and advice from their teachers, the learning adventure could be planned in a more focused manner and they would be able to perform advanced research and assignments as part of their enrichment programme.

The planning and development of enrichment programme for the gifted education agenda should consider the students' learning style to assist them in developing their full potential and encourage critical thinking and creativity in their tasks and assignments. Renzulli's enrichment model suggested learning activities that would challenge students to research on a certain topic of their interest in depth as it would enhance their cognitive ability during the process of learning. Thus, the educator should always consider individual's strength and ability in choosing and writing the activities and assignments' goals so that it would match the gifted students own strengths and interests. Once the learning style and individual profiles are set, the proposed activities could be prepared and later assessed for its effectiveness. Modification and improvement could be made later to continuously improve the quality of the enrichment programme. This development cycle would be part of the gifted education programme to ensure the standard would be met and the students' needs and requirements are met.

\section{Recommendations}

It is mentioned above how important it is to equip children, who are the future workforce and leaders of this country, with $21^{\text {st }}$ Century Skills and mould education policies using this framework. Based on this, there are various recommendations below for both policymakers and teachers.

\section{Recommendations for policymakers}

- The Ministry of Education would consider using the MOOC approach in assisting the teaching and learning process for the primary and secondary schools. The digitalisation effort made by the government would take a new approach in getting teaching and learning resources available online ready to be accessed anytime and anywhere.

- Developing MOOC for schools is a skill that many teachers would have mastered easily with the right training and support by the ministry of education. There are already established MOOCs at 
the tertiary level and experts among the higher learning institution's lecturers familiar with this platform.

- Online learning is the future that would become part of the education system and using this approach would prepare educators with one of the most accessible platforms available online. The schools and educators do not have to build it from zero and it eliminates the technical issues dealing with this.

- In $21^{\text {st }}$ Century Learning Skills, digital literacies would be important for the educators and students. Creating a digital literacy standard for both teachers and students would be a move in the right direction.

- Technology skills and aptitude should be integrated into the curriculum and the syllabus should always consider the needs and requirements of the target population students involved.

\subsection{Recommendations for teachers}

- Identifying and developing these skills among fellow educators and students in their institution would accelerate the effort in making MOOC platform a useful form of teaching and learning resource.

- Teachers may need to create a support system for fellow educators in ensuring the smooth transition in the field of e-learning in schools. Continuous training and support off- and online for the teaching staff would benefit them in short and long-term effort to make this a successful programme.

\subsection{Acknowledgement}

This study was made possible with the assistance from Research Management Centre, Universiti Sains Islam Malaysia. The team would also like to acknowledge the support given by Kolej GENIUS Insan and all the students involved in the study.

\section{References}

5 Pillars of Social Learning Design. (2020). OpenLearning white paper.

Bakar, A.Y.A. (2017). Developing Gifted and Talented Education Program: The Malaysian Experience. Creative Education, 8, 1-11. http://dx.doi.org/10.4236/ce.2017.81001

Balakrishnan, V., \& Gan, C. L. (2016). Students' learning styles and their effects on the use of social media technology for learning. Telematics and Informatics, 33(3), 808-821.

Beecher, M., \& Sweeny, S. M. (2008). Closing the achievement gap with curriculum enrich- ment and differentiation: One school's story. Journal of Advanced Academics, 19, 502-530.

Brigandi, C. B. (2019). Fidelity of Implementation for an Evidence-Based Enrichment Practice. Journal of Advanced Academics, 30(3), 268-297. https://doi.org/10.1177/1932202X19862686

Ellsworth, A. (2018). Assistive technology for gifted and talented students. Retrieved from https://study.com/ academy/lesson/assistive-technology-for-gifted-talented-students.html

Gagne, F. (2005). From gifts to talents: the DMGT as a developmental model. In Sternberg \& Davidson 2005, 98-119.

Gagné, F. (2015). Academic talent development programs: a best practices model. Asia Pacific Education Review, 16. 10.1007/s12564-015-9366-9. 
Hammouri, K. (2020). The Effectiveness of a Biotechnology Enrichment Training Program in Improving Gifted Students' Reflective Thinking Skills and Academic Achievement. Humanities and Management Sciences-Scientific Journal of King Faisal University. https://doi.org/10.37575/h/edu/2189

Hertberg-Davis, H. L., \& Callahan, C. M. (2013). Introduction. In H. L. Hertberg-Davis \& C. M. Callahan (Eds.), Fundamentals of Gifted Education (pp. 1-10). New York, NY: Routledge.

Housand, B. C., \& Housand, A. M. (2012). The role of technology in gifted students' motivation. Psychology in the Schools, 49(7), 706-715. doi: 10.1002/pits.21629

Jelinek, K. R. (2013). A produção do sujeito de altas habilidades: os jogos de poder- linguagem nas práticas de seleção e enriquecimento educativo. Tese de Doutorado, Educação, Universidade Federal do Rio Grande do Sul, Porto Alegre. In Rambo \& Fernandes, 2019, p. 131.

Jiyoon Yoon, Kyoung Jin Kim, \& Katie Koo. (2020). Enrichment program for the ethnic minority of gifted and talented students in science and engineering, International Journal of Science Education, Part B, DOI: 10.1080/21548455.2020.1714092

Mady, M. A., \& Baadel, S. (2020). Technology- Enabled Learning (TEL): YouTube as a Ubiquitous Learning Aid. Journal of Information \& Knowledge Management, 19(01), 2040007. doi:10.1142/S0219649220400079.

Kamis, M.S., Alias, M.N., Lubis, M.A., Mikeng, D., Abidin, S.G.Z., Ismail, M.J., \& Yusof, R. (2021). Learning Arabic using telegram in the laptop: The language learning style of Malaysian gifted learners. Journal of Language and Linguistic Studies, 17(1), 591-599. Doi: 10.52462/jlls.40

Kulik, J. A., \& Kulik, C. L. C. (1992). Meta-analytic Findings on Grouping Programs. Gifted Child Quarterly, 36(2), 73-77. https://doi.org/10.1177/001698629203600204.

Loveless, T., Farkas, S., \& Duffett, A. (2008). High-achieving students in the era of NCLB. Washington, DC: Thomas B. Fordham Institute.

Olenchak, F. R., \& Renzulli, J. S. (1989). The Effectiveness of the Schoolwide Enrichment Model on Selected Aspects of Elementary School Change. Gifted Child Quarterly, 33, 36-46. https://doi.org/10.1177/001698628903300106

Olszewski-Kubilius, P. \& Lee. S. (2004). Gifted adolescents' talent development through distance learning. Journal of Educational Gift, 28, 7-35. https://doi.org/10.1080/02783190409554261

Pfeiffer, SI., Shaunessy-Dedrick E, Foley-Nicpon, M., eds. (2018). APA Handbook of Giftedness and Talent. Washington, DC: Am. Psychol. Assoc.

Periathiruvadi, Sita., \& Rinn, Anne N. (2012). Technology in Gifted Education: A Review of Best Practices and Empirical Research. Journal of Research on Technology in Education; Winter 2012/2013, 45(2), ProQuest Central pg. 153.

Rambo, M. C. D., \& Fernandes, S. H. A. A. (2019). Proposal of enrichment activities for students with indicative of high skills/giftedness in Mathematics. Acta Scientiae, 21(5), 128-144. https://doi.org/10.17648/acta.scientiae.4959

Reis, S. (2007). No child left bored. School Administrator, 64(2), 22-26.

Renzulli, J. S. (1999). What is this thing called giftedness, and how do we develop it? A twenty-fiveyear perspective. Journal for the Education of the Gifted, 23(1), 3-54. 
Renzulli, J. S., \& Reis, S. M. (1997). The schoolwide enrichment model: A comprehensive plan for educational excellence. Mansfield Center, CT: Creative Learning Press.

Renzulli J. S., and Reis, S. M. (2012). A virtual learning application of the schoolwide enrichment model and high-end learning theory. Gifted Education International, 28(1), 19-40.

Rotigel, J., \& Fello, S. (2004). Mathematically gifted students: How can we meet their needs? Gifted Child Today, 27(4), 46-65.

Sak, U., \& Ayas, B. (2020). EPTS Curriculum Model: Optimum curriculum differentiator for the education of gifted students. Gifted Education International, 36(2), 154-169. https://doi.org/10.1177/0261429420917879

Sosas, R.V. (2021). Technology in teaching speaking and its effects to students learning English. Journal of Language and Linguistic Studies, 17(2), 958-970. Doi: 10.52462/jlls.66

Stambaugh, T., \& Pierce, J. (2019). Assistive Technology and the Gifted Learner. In Encyclopedia of Education and Information Technologies (pp. 1-5). Springer International Publishing. Doi: 10.1007/978-3-319-60013-0_150-1

Sternberg, RJ., Davidson, JE., eds. (2005). Conceptions of Giftedness. Cambridge, UK: Cambridge University Press. 2nd ed.

Taber, Keith. (2020). Enriching School Science for The Gifted Learner. Gatsby Science Enhancement Programme. Cambridge, UK.

Tan, L. S., Ponnusamy, L. D., Lee, S. S., Koh, E., Koh, L., Tan, J. Y., ... Chia, T. T. S. A. (2020). Intricacies of designing and implementing enrichment programs for high-ability students. Gifted Education International, 36(2), 130-153. https://doi.org/10.1177/0261429420917469

VanTassel-Baska, J. (1992). Planning effective curriculum for gifted learners. Denver, CO: Love.

VanTassel-Baska, J. (2003). Curriculum Planning and Instructional Design for Gifted Learners. Denver, CO: Love Publishing.

VanTassel-Baska, J., \& Brown, E. F. (2009). An analysis of gifted education curriculum models. Methods and materials for teaching the gifted, 75-106.

Wallace, P. (2009). Distance learning for gifted students: outcomes for elementary, middle, and high school aged students. Journal of Educational Gift, 32, 295-320.

Worrell, F. C., Subotnik, R. F., Olszewski-Kubilius, P., \& Dixson, D. D. (2019). Gifted students. Annual review of psychology, 70, 551-576.

Yaacob, Z. and Saad, N. H. M. (2020). Acceptance of YouTube as a Learning Platform during the Covid-19 Pandemic: The Moderating Effect of Subscription Status. Technology, Educatıon, Management, Informatıcs, 9(4), 1732-1739. doi: 10.18421/TEM94-54

Yu, H. P., \& Jen, E. (2020). Integrating Nanotechnology in the Science Curriculum for Elementary High-Ability Students in Taiwan: Evidenced-Based Lessons. Roeper Review, 42(1), 38-48. doi: 10.1080/02783193.2019.1690078

Zhou, Q., Lee, C. S., Sin, S. C. J., Lin, S., Hu, H., \& Ismail, M. F. F. B. (2020). Understanding the use of YouTube as a learning resource: a social cognitive perspective. Aslib Journal of Information Management. doi:10.1108/AJIM-10-2019-0290. 


\section{AUTHOR BIODATA}

Zulkarnin Zakaria is English language communication lecturer in Kolej GENIUS Insan, Universiti Sains Islam Malaysia. He obtained his B.Ed. TESL (Hons) from UKM and M.Ed. TESL (Hons) from UiTM. His research interests include gifted education, educational technology, instructional design, social learning media and second language learning and teaching.

Mahiz Spawi is a lecturer at Kolej GENIUS Insan, Universiti Sains Islam Malaysia (USIM). His areas of specialization include History and Civilization, History Education, Historical Thinking Skills, Da'wah and Islamic Management, Gifted and Talented Education.

Mohd Zamrus Mohd Ali is a lecturer at Kolej GENIUS Insan, Universiti Sains Islam Malaysia. His research areas cover the field of Islamic Studies, History and Philosophy of Islamic Science, Islamic Civilization, Al-Quran and Al-Sunnah Education, Islamic Shariah Education. He has been conducting training in these areas: Al-Quran - tahfiz, tajwid and ulum; Islamic motivation - teaching of Al-Quran for educators.

Ahmad Fuad Mohamad Amin is an academic at Kolej GENIUS Insan, Universiti Sains Islam Malaysia, teaching history, philosophy and research. He received his doctorate and master's degree in Educational Psychology from Universiti Kebangsaan Malaysia. His study covers psychology, sociology, history, and research in education. He has been involved in students' research supervision and publication. He is also active in academic book publishing

Rossidi Usop is a doctorate holder in Economics from UNISZA, Malaysia and currently a senior lecturer at Kolej GENIUS Insan, Universiti Sains Islam Malaysia. His research interests are contemporary entrepreneurship, Islamic entrepreneurship, Islamic economics, Islamic business ethics and qualitative research approach. 